\title{
What Matters in Weight Loss? An In-Depth Analysis of Self-Monitoring
}

Stefanie Lynn Painter ${ }^{1 *}$, LD, RD, DHEd; Rezwan Ahmed ${ }^{2 *}$, PhD; James O Hill ${ }^{3}$, PhD; Robert F Kushner ${ }^{4}$, MD; Richard Lindquist ${ }^{5}$, MD; Scott Brunning ${ }^{2}$, MS; Amy Margulies ${ }^{2}$, LDN, CDE, RD

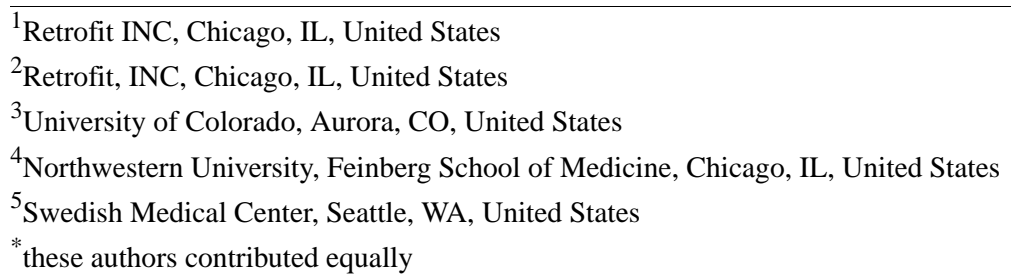

Corresponding Author:

Stefanie Lynn Painter, LD, RD, DHEd

Retrofit INC

123 N. Wacker Drive

Suite 1250

Chicago, IL, 60606

United States

Phone: 18007745962

Fax: 18007745962

Email: stefanie@ retrofitme.com

\section{Abstract}

Background: Using technology to self-monitor body weight, dietary intake, and physical activity is a common practice used by consumers and health companies to increase awareness of current and desired behaviors in weight loss. Understanding how to best use the information gathered by these relatively new methods needs to be further explored.

Objective: The purpose of this study was to analyze the contribution of self-monitoring to weight loss in participants in a 6-month commercial weight-loss intervention administered by Retrofit and to specifically identify the significant contributors to weight loss that are associated with behavior and outcomes.

Methods: A retrospective analysis was performed using 2113 participants enrolled from 2011 to 2015 in a Retrofit weight-loss program. Participants were males and females aged 18 years or older with a starting body mass index of $\geq 25 \mathrm{~kg} / \mathrm{m} 2$, who also provided a weight measurement at the sixth month of the program. Multiple regression analysis was performed using all measures of self-monitoring behaviors involving weight measurements, dietary intake, and physical activity to predict weight loss at 6 months. Each significant predictor was analyzed in depth to reveal the impact on outcome.

Results: Participants in the Retrofit Program lost a mean -5.58\% (SE 0.12) of their baseline weight with 51.87\% (1096/2113) of participants losing at least $5 \%$ of their baseline weight. Multiple regression model $\left(\mathrm{R}^{2}=.197, P<0.001\right)$ identified the following measures as significant predictors of weight loss at 6 months: number of weigh-ins per week $(P<.001)$, number of steps per day $(P=.02)$, highly active minutes per week $(P<.001)$, number of food log days per week $(P<.001)$, and the percentage of weeks with five or more food logs $(P<.001)$. Weighing in at least three times per week, having a minimum of 60 highly active minutes per week, food logging at least three days per week, and having $64 \%(16.6 / 26)$ or more weeks with at least five food logs were associated with clinically significant weight loss for both male and female participants.

Conclusions: The self-monitoring behaviors of self-weigh-in, daily steps, high-intensity activity, and persistent food logging were significant predictors of weight loss during a 6-month intervention.

(J Med Internet Res 2017;19(5):e160) doi: 10.2196/jmir.7457

\section{KEYWORDS}

behavior; body mass index; fitness trackers; self-monitoring; obesity; overweight; weight loss 


\section{Introduction}

Self-monitoring is commonly used in weight-loss regimens to increase awareness of current and desired behaviors. Both consumers and health companies are incorporating self-monitoring technology through mobile phone apps, smart scales, and other wearable devices into their weight-loss programs. However, understanding how to best use the information being gathered by this relatively new technology needs more rigorous study, especially with recent controversy regarding the benefits of wearable activity trackers $[1,2]$. According to the Centers for Disease Control and Prevention (CDC), $36.5 \%$ of adults are classified as obese in the United States and US $\$ 147$ billion is spent on obesity-related medical costs per year; therefore, determining whether and how self-monitoring contributes to weight loss is important for improving the health of the overall population [3].

Standard behavioral treatment in obesity includes dietary and physical activity counseling and self-monitoring of body weight, activity, and diet [4]. Behavioral weight-loss interventions up to 12 months have average outcomes between $5 \%$ to $10 \%$ weight loss [5-11]. Although clinically significant, the studies reviewed showed less than half of participants are successful at losing $5 \%$ or more of their weight $[6,7,12-14]$.

Regular self-weighing or weighing in a consistent pattern over time provides awareness to specific behaviors, situations, or environments that could promote desired or undesired changes in weight. Self-weighing correlates with successful weight loss and has been shown to significantly increase weight loss success in the first 6 months of an intervention [15-18]. Specifically, a minimum of weekly self-weigh-ins has been shown to be effective; however, a higher frequency of self-weigh-ins more than once per week increases weight-loss outcomes [19-24]. Once a consistent pattern of self-weighing has been established, not weighing for more than a month increases likelihood of weight gain, as shown by Helander et al [15].

Both wearing an activity tracker and setting a step goal are associated with lower body mass index (BMI) and an increase in activity [25]. The average American gets 5117 steps per day [26]. High step averages were associated with younger, single males with higher education and lower BMI $\left(\mathrm{kg} / \mathrm{m}^{2}\right)$ [26]. Individuals with obesity averaged 1500 fewer steps per day than normal or overweight individuals [26]. Modest weight loss has been shown with pedometer interventions [27,28]. By setting individualized physical activity goals around steps per day and active minutes per day, participants are more likely to increase and maintain physical activity postintervention [29]. More frequent self-monitoring and higher adherence are related to greater physical activity over time, which can lead to a greater decrease in weight at 6 months [30].

Dietary self-monitoring with feedback can improve clinically significant weight-loss outcomes [31-34], whereas personalized feedback can improve consistency of dietary self-monitoring
$[34,35]$. Consistency has the greatest association between dietary self-monitoring and achieving clinically significant weight loss [31-34,36]. Self-monitoring for consecutive days is linked to greater outcomes, such as logging at least one food log entry per day has been shown to increase weight loss $[31,32]$.

The purpose of this study was to analyze the self-monitoring behaviors of participants around weight, activity, and nutrition in a 6-month weight-loss intervention administered by Retrofit (see Multimedia Appendix 1), a personalized weight-management and Web-based disease-prevention solution. The self-monitoring behaviors were evaluated for their association with weight loss to determine the level of impact on predicting weight loss outcomes. Additionally, each high impact behavior was evaluated independently to assess the association between the behavior and weight loss to determine best practices around self-monitoring recommendations. The analysis of the significant self-monitoring behaviors focused on understanding the following questions:

1. What is the association between a participant's level of self-monitoring and weight loss?

2. What is the association between different levels of weight loss outcomes and the corresponding participant's commitment to self-monitoring?

\section{Methods}

\section{Study Design}

A retrospective analysis was performed to assess the effect of various self-monitoring behaviors during a 6-month weight-loss intervention using de-identified data from the Retrofit weight-loss program.

\section{Participants}

Participants in the study were paying customers of the Retrofit Program who enrolled through the direct-to-consumer website [37] or through an employer-sponsored program. Customers were considered as eligible study participants if they were age at least 18 years; had a starting BMI of $25 \mathrm{~kg} / \mathrm{m}^{2}$ or higher; had signed up for the program between September 27, 2011 and December 31, 2015; and provided at least one weight measurement beyond baseline measurement. Participants were considered to have completed the program if they provided a weight measurement at the sixth month of their program. A total of 3166 customers satisfied all inclusion criteria to be study participants (Figure 1). Approximately 80.35\% (2544/3166) of the study participants were direct-to-consumer customers and the remaining $19.65 \%(622 / 3166)$ were part of an employer-sponsored program. A total of 2113 (66.74\%) participants completed the 6-month program. All customers who satisfied the inclusion criteria and provided a weight at 6 months were included as participants. No customer was removed or eliminated from the population due to a lack of success on the program. 
Figure 1. Study population with inclusion / exclusion criteria.

\begin{tabular}{|c|}
\hline Study Population \\
\hline $\begin{array}{l}\text { Inclusion Criteria: } \\
\text { 1. Starting BMI } \geq 25 \\
\text { 2. Age } \geq 18 \\
\text { 3. Started before Dec } 31,2015 \\
\text { 4. Provided at least } 1 \text { weight } \\
\text { measurement after baseline }\end{array}$ \\
\hline$N=3166$ \\
\hline 6-Month Completers \\
\hline $\begin{array}{l}\text { Exclusion Criteria: } \\
\text { Missing weight at } 6 \text { month } \\
\text { Excluded }=1003\end{array}$ \\
\hline$N=2113$ \\
\hline
\end{tabular}

\section{Retrofit Program}

The analysis included data from six Retrofit programs: Expert 10 Weight-Loss Program, Expert 15 Weight-Loss Program, Advisor Weight-Loss Program, Jump Start Program, Retrofit Program, and Sustain Program. The Expert 10, Expert 15, Advisor, and Sustain programs were designed with a 6-month weight-loss phase and an additional 6-month weight maintenance phase. The Retrofit Program was designed with a 6-month weight-loss phase only with the option to continue into a maintenance program called Retrofit Next. The Jump Start Program was designed with a 3-month weight-loss phase only with the option to continue into Retrofit Next.

As part of the Retrofit weight-loss protocols, all participants are taught and encouraged to adhere to the same self-monitoring recommendations. All programs provided participants with the same technology, access to a weight-loss expert, education, accountability, feedback, and the opportunity to communicate with an expert coach via Web-based messages. Additional details of the Retrofit Program and expert coach qualifications can be found in a previous publication [38].

The participant was provided a Fitbit activity tracker, Wi-Fi-enabled scale, and access to a private dashboard (see Multimedia Appendix 2). The private dashboard allowed each participant to keep a personal food and exercise log, review his or her personal data, and enabled communication between the participant and his or her expert coach through a Web-based electronic messaging feature (see Multimedia Appendix 3). The private dashboard was accessed via the Retrofitme Web app, mobile website, or mobile phone app, which was available on Apple iOS and Android platforms.

Participants were encouraged to weigh in daily, wear their activity tracker daily, achieve their personalized daily step goal, and $\log$ all food and beverage choices consumed throughout the day. Expert coaches personalized participant's step goals by recommending the participants to increase step counts in increments of 500 to achieve their personal daily step goal at 6 months.

\section{Measures}

\section{Weight}

Participants were provided a Wi-Fi-enabled scale that securely transmitted weight data over the Internet to a Retrofit central data server. Participant weight data were collected through the use of the provided Wi-Fi scale $(99.39 \%, 556,630 / 560,043$ of recorded weights) or self-reported entry $(0.61 \%, 3413 / 560,043)$. Instructions were provided for scale set up, as well as the option for help through Retrofit's customer support. Self-reported entry was permissible if a participant had difficulty setting up their Wi-Fi scale. Expert coaches reviewed weight data during 1:1 coaching sessions to confirm weight accuracy. Baseline weight was considered as the first weight measurement received from the participant during week 1 . Percentage of baseline weight lost at 6 months was calculated and used as the primary outcome. Two weigh-in metrics were calculated to quantify participants' adherence to self-monitoring behavior and the potential impact of self-weigh-ins on weight loss: (1) the number of weigh-ins per week and (2) the percentage of weeks participants weighed in at least three times.

\section{Activity}

Participants were encouraged to wear Fitbit activity trackers every day. Activity data from any version of Fitbit activity trackers, such as steps, distance, calories burned, active minutes, etc, were wirelessly uploaded to Fitbit.com and later automatically synced to participants' personal Retrofit dashboards. Participants did not have the option to self-report activity data. A total of five different metrics were calculated to understand the impact of activity on weight loss. The number of tracker usage days per week was calculated to monitor participant engagement. Step count per day was considered one 
of the metrics for measuring participant activity. To measure the intensity of the activities, three levels of active minutes were tracked. Fitbit trackers continuously estimate users' metabolic equivalents (METs) by calculating the intensity of the activity and classifying the active minutes as high, moderate, or low following the CDC's recommendation [28].

\section{Nutrition Tracking / Food Logging}

A private online/mobile dashboard allowed participants to track personal food logs. Participants were able to log meals, snacks, treats, and beverages along with the description, quantity, and photo of the food. Each individual meal, snack, treat, and/or beverage was considered a food $\log$ entry. Four food logging-specific measures were calculated to quantify participants' adherence to food logging behavior and the potential impact of food logging on weight loss. The number of days participants logged food entries per week and the number of food log entries per week were calculated to measure the level of adherence to the behavior of food logging. The following two measures were introduced to measure participants' engagement through food logging over the 6-month intervention: the percentage of weeks participants logged at least five food $\log$ entries and at least 15 food log entries.

\section{Statistical Analysis}

All measures associated with self-monitoring behaviors involving weight measurements, dietary intake, and physical activity were included in a multiple regression analysis to predict weight loss during the intervention. Measures with statistically significant contribution to predicting weight loss were identified. To determine self-monitoring behaviors/measures that could be considered as significant predictors of weight loss, three primary regression models were built. The first primary regression model assessed two weigh-in-related measures as predictors of weight loss. The second model included five activity-related measures as predictors of weight loss. The third primary regression model assessed four measures related to food logging as predictors of weight loss. All the significant predictors (ie, self-monitoring behaviors/measures) from the primary regression model were included in an overall regression model that considered all behaviors as predictors of weight loss. The significant predictors of the overall model were considered to be the most important measures/behaviors for weight loss. Finally, each significant self-monitoring measure was analyzed in depth to reveal the impact on outcomes during the intervention period to capture the significant association between high-level monitoring to higher outcome levels. For each behavior, one-way ANOVA tests were performed to determine the association between behavior frequency and weight loss and compare behavior frequency of participants with different weight-loss levels.

Data analyses were performed using $\mathrm{R}$ version 3.2.3, which included dplyr 0.4.3, ggplot2 2.1.0, data.table 1.9.6, and leaps 2.9 packages. In addition, $t$ tests of equal variance were conducted on continuous variables at baseline and subsequent time points for two group comparisons. One-way ANOVA was utilized to determine mean differences for greater than two group comparisons. Subsequent Tukey tests were conducted to determine mean differences. Chi-square analyses were performed to determine differences among categorical variables when appropriate. To perform best subset selection in a multiple regression analysis, an "all possible regressions" method was used to derive the best-fitting overall model using the leaps package. Alpha was set at .05 for all statistical tests to determine statistical significance.

\section{Results}

The reported results are based on the retrospective analysis evaluating the effect of various self-monitoring behaviors during a weight-loss intervention using 2113 of 3166 participants (66.74\%) who completed the Retrofit 6-month weight-loss program.

\section{Baseline Characteristics}

Table 1 shows the demographic details of participants at baseline. There were no differences in age and starting BMI at baseline between male and female participants. Male participants had a higher starting weight $(P<.001)$. There were no differences between completers and noncompleters in starting weight $(P=.07)$ or starting BMI $(P=.55)$, but completers had a higher mean age (mean 44.54, SD 10.72 years vs mean 42.01, SD 10.69 years, $P<.001$; see Multimedia Appendix 4, Table S1).

\section{Weight Change at 6 Months}

The mean weight loss at 6 months was $-5.58 \%$ (SE 0.12), the mean change in BMI was -1.91 (SE 0.04), and $51.87 \%$ $(1096 / 2113)$ of participants lost $5 \%$ or more of their baseline weight (see Table 2). Male participants lost a higher percentage of weight $(P=.02)$ and had a higher BMI change $(P=.01)$ than female participants. However, there were no significant differences between males and females in terms of the percentage of group losing $5 \%$ or more weight at 6 months.

Table 1. Baseline demographics of participants.

\begin{tabular}{lllll}
\hline Demographics & Total, mean $(\mathrm{SD})(\mathrm{N}=2113)$ & Male, mean $(\mathrm{SD})(\mathrm{n}=860)$ & Female, mean $(\mathrm{SD})(\mathrm{n}=1253)$ & $P$ \\
\hline Age $($ years $)$ & $44.54(10.72)$ & $44.61(10.98)$ & $44.49(10.54)$ & .81 \\
Starting weight, $(\mathrm{kg})$ & $99.76(22.92)$ & $110.56(22.43)$ & $92.35(20.14)$ & $<.001$ \\
Starting BMI $\left(\mathrm{kg} / \mathrm{m}^{2}\right)$ & $33.84(6.80)$ & $34.03(6.35)$ & $33.71(7.09)$ & .27 \\
\hline
\end{tabular}


Table 2. Weight-loss outcomes at 6 months.

\begin{tabular}{lllll}
\hline Outcome measures & Total, mean $(\mathrm{SE})(\mathrm{N}=2113)$ & Male, mean $(\mathrm{SE})(\mathrm{n}=860)$ & Female, mean $(\mathrm{SE})(\mathrm{n}=1253)$ & $P$ \\
\hline Weight loss $(\%)$ & $-5.58(0.12)$ & $-5.90(0.12)$ & $-5.36(0.12)$ & .02 \\
BMI change & $-1.91(0.04)$ & $-2.04(0.07)$ & $-1.82(0.05)$ & .01 \\
Lost 5\% of baseline weight $(\%)$ & $51.87(0.01)$ & $54.30(0.02)$ & $50.20(0.01)$ & .07 \\
\hline
\end{tabular}

Table 3. Multiple regression models identifying predictors of weight loss at 6 months.

\begin{tabular}{|c|c|c|c|c|c|c|}
\hline \multirow[t]{2}{*}{ Models } & \multicolumn{3}{|l|}{ Coefficients } & \multicolumn{3}{|c|}{ Model summary } \\
\hline & Beta (SE) & $t(\mathrm{df})$ & $P$ & $R^{2}$ & Adjusted $R^{2}$ & $P$ \\
\hline Self-weigh-in & & & & .103 & .102 & $<.001$ \\
\hline Weigh-ins/week (n) & $-1.25(0.19)$ & $-6.54(2110)$ & $<.001$ & & & \\
\hline Weeks with $\geq 3$ weigh-ins (\%) & $0.018(0.01)$ & $1.59(2110)$ & .11 & & & \\
\hline Activity & & & & .152 & .150 & $<.001$ \\
\hline Tracker days/week & $-0.54(0.10)$ & $-5.419(2107)$ & $<.001$ & & & \\
\hline Steps/day & $-0.0002(0.0001)$ & $-1.863(2107)$ & .06 & & & \\
\hline Highly active minutes/day & $-0.06(0.01)$ & $-4.288(2107)$ & $<.001$ & & & \\
\hline Fairly active minutes/day & $0.003(0.004)$ & $0.693(2107)$ & .49 & & & \\
\hline Lightly active minutes/day & $-0.002(0.003)$ & $-0.818(2107)$ & .41 & & & \\
\hline Nutrition/food logging & & & & .123 & .121 & $<.001$ \\
\hline Food logs/week (n) & $0.01(0.04)$ & $0.245(2108)$ & .81 & & & \\
\hline Food log days/week (n) & $-1.92(0.20)$ & $-9.362(2108)$ & $<.001$ & & & \\
\hline Weeks with $\geq 5$ logs (\%) & $0.08(0.01)$ & $5.935(2108)$ & $<.001$ & & & \\
\hline Weeks with $\geq 15 \operatorname{logs}(\%)$ & $-0.01(0.01)$ & $-0.654(2108)$ & .51 & & & \\
\hline Overall & & & & .197 & .194 & $<.001$ \\
\hline Weigh-ins/week (n) & $-0.417(0.07)$ & $-5.619(2106)$ & $<.001$ & & & \\
\hline Tracker days/week (n) & $-0.112(0.10)$ & $-1.081(2106)$ & .28 & & & \\
\hline Steps/day (n) & $-0.0001(0.00006)$ & $-2.269(2106)$ & .02 & & & \\
\hline Highly active mins/day (n) & $-0.05(0.01)$ & $-4.420(2106)$ & $<.001$ & & & \\
\hline Food log days/week (n) & $-1.30(0.19)$ & $-6.777(2106)$ & $<.001$ & & & \\
\hline Weeks with $\geq 5$ logs (\%) & $0.06(0.01)$ & $5.097(2106)$ & $<.001$ & & & \\
\hline
\end{tabular}

\section{Identifying Behaviors That Matter}

\section{Model for Self-Weigh-In Behavior as a Predictor of Weight Change}

To identify important self-weigh-in measures for predicting weight change, a regression model was built $\left(R^{2}=.103, P<.001\right)$ containing the number of weigh-ins per week and the percentage of weeks with three or more weigh-ins. Table 3 shows that only the number of weigh-ins per week was identified as a significant predictor of weight change $(P<.001)$.

\section{Model for Activity-Related Behaviors as Predictor of Weight Change}

To identify significant activity-related measures, a multiple regression model was constructed $\left(R^{2}=.152, P<.001\right)$ containing the number of activity tracker usage days per week, the number of steps per day, and the number of highly, fairly, and lightly

active minutes per day. Table 3 displays that the number of activity tracker days per week $(P<.001)$ and the number of highly active minutes per day $(P<.001)$ were significant predictors of weight change. Though the number of steps per day was not significant $(P=.06)$, it was selected to be included as a predictor for weight change in the overall model based on previous study indications [27,30,39].

\section{Model for Food Logging-Related Behaviors as a Predictor of Weight Change}

To identify significant nutrition/food logging-related measures, a multiple regression model was constructed $\left(R^{2}=.123, P<.001\right)$ containing the number of food logs per week, the number of food log days per week, the percentage of weeks with five or more food logs, and the percentage of weeks with 15 or more food logs. Table 3 shows that the number of food log days and the percentage of weeks with five or more food logs were significant predictors of weight change. 


\section{Overall Multiple Regression Model}

An overall regression model was built to predict weight change at 6 months by including all significant predictors from the self-weigh-in, activity, and food logging model. This multiple regression model $\left(R^{2}=.197, P<.001\right)$ included the number of weigh-ins per week, the number of tracker usage days per week, the number of steps per week, the number of highly active minutes per week, the number of food log days per week, and the percentage of weeks with five or more food logs. Except the tracker usage days per week, all other behaviors/measures were found to be significant predictors of weight change, as shown in Table 3.

To further verify the significance of the selected behaviors/measures, an "all possible regressions" method was used to derive the best-fitting overall model. This approach of model selection determined the final model by performing an exhaustive search for the best subsets of the 11 measures listed under the primary regression models for predicting weight loss. All possible regressions included only the main effects; interactions were beyond the scope of this analysis. The best regression model contained the same five significant predictors of the overall model reported in Table 3. The next section focuses on analyzing the five significant predictors.

\section{The Five Significant Predictors of Weight Loss}

\section{Self-Weigh-In}

Based on the self-weigh-in data from 0 to 6 months, a higher weigh-in frequency was significantly associated with a higher level of weight loss at 6 months. Clinically significant weight loss $(5 \%)$ was associated with at least three weigh-ins per week (see Table 4). The results of one-way ANOVA showed a significant difference of mean weight loss between different weigh-in levels $(P<.001)$. A subsequent Tukey test confirmed the significant differences between the " $\geq 5$ " weigh-in level and the remaining three levels $(P<.001$ for all $)$ and between weigh-in levels " 3 to 4 " and "1 to 2 " $(P=.002)$ and between weigh-in levels " 3 to 4 " and " $<1$ " $(P=.02)$. Similar ANOVA tests were performed on male and female participants separately and a significant difference in mean weight loss between different weigh-in levels was found (male: $P<.001$; female: $P<.001$; see Multimedia Appendix 4, Table S2).

The analysis of self-weigh-in frequency of participants with different levels of weight loss showed that a higher weigh-in frequency was significantly associated with groups with higher levels of weight loss. Figure 2 presents the mean weekly weigh-in frequency among participants of three outcome levels: "lost $\geq 10 \%$ " (388/2113, 18.36\%), "lost 5\%-10\%" (707/2113, $34.46 \%)$, and "lost $<5 \%$ " (1018/2113, 48.18\%). For all other analyses throughout the paper, behavior frequency based on outcome levels uses the same outcome-based participant groups. It showed a clear difference in weigh-in frequency throughout the 6-month program. The mean weigh-in frequencies over 6 months were mean 4.70 (SE 0.09), mean 4.21 (SE 0.07), and mean 3.40 (SE 0.05) weigh-ins per week for the lost $\geq 10 \%$, lost $5 \%-10 \%$, and lost $<5 \%$ groups, respectively $(P<.001)$. Additional ANOVA tests performed on male and female participants separately showed a similar significant difference of mean weigh-in frequency between different outcome levels (male: $P<.001$; female: $P<.001$, see Multimedia Appendix 4, Table S3). 
Table 4. Weight-loss outcomes of participants for different behavior frequencies.

\begin{tabular}{|c|c|c|c|}
\hline Self-monitoring behaviors & $\mathrm{n}(\%)$ & Weight loss (\%), mean (SE) & $P$ \\
\hline Weigh-in frequency per week & & & $<.001$ \\
\hline$<1$ & $89(4.21)$ & $-3.41(0.58)$ & \\
\hline $1-2$ & $636(30.10)$ & $-4.08(0.20)$ & \\
\hline $3-4$ & $690(33.65)$ & $-5.09(0.19)$ & \\
\hline$\geq 5$ & $698(33.03)$ & $-7.82(0.20)$ & \\
\hline Steps per day & & & $<.001$ \\
\hline$<5000$ & $797(37.72)$ & $-3.68(0.17)$ & \\
\hline $5000-7499$ & $604(28.58)$ & $-5.56(0.20)$ & \\
\hline $7500-9999$ & $429(20.30)$ & $-7.03(0.26)$ & \\
\hline$\geq 10,000$ & $283(13.39)$ & $-9.03(0.34)$ & \\
\hline Highly active minutes per week & & & $<.001$ \\
\hline$<60$ & $897(42.41)$ & $-4.14(0.17)$ & \\
\hline $60-119$ & $525(24.82)$ & $-5.71(0.21)$ & \\
\hline $120-179$ & $299(14.14)$ & $-5.85(0.29)$ & \\
\hline$\geq 180$ & $394(18.63)$ & $-8.64(0.28)$ & \\
\hline Food log days per week & & & $<.001$ \\
\hline$<1$ & $316(14.96)$ & $-3.67(0.33)$ & \\
\hline $1-2$ & $596(28.21)$ & $-4.32(0.20)$ & \\
\hline $3-4$ & $565(26.74)$ & $-5.15(0.19)$ & \\
\hline$\geq 5$ & $636(30.10)$ & $-8.20(0.21)$ & \\
\hline Food logs per week & & & $<.001$ \\
\hline$<5$ & $617(29.20)$ & $-4.37(0.21)$ & \\
\hline $5-9$ & $405(19.17)$ & $-4.66(0.24)$ & \\
\hline $10-14$ & $297(14.06)$ & $-5.11(0.29)$ & \\
\hline $15-19$ & 247 (11.69) & $-5.46(0.32)$ & \\
\hline$\geq 20$ & 547 (25.89) & $-8.10(0.23)$ & \\
\hline
\end{tabular}

Figure 2. Weekly mean weigh-in frequency of participants between 0 and 6 months. Error bars indicate the standard error of the mean.

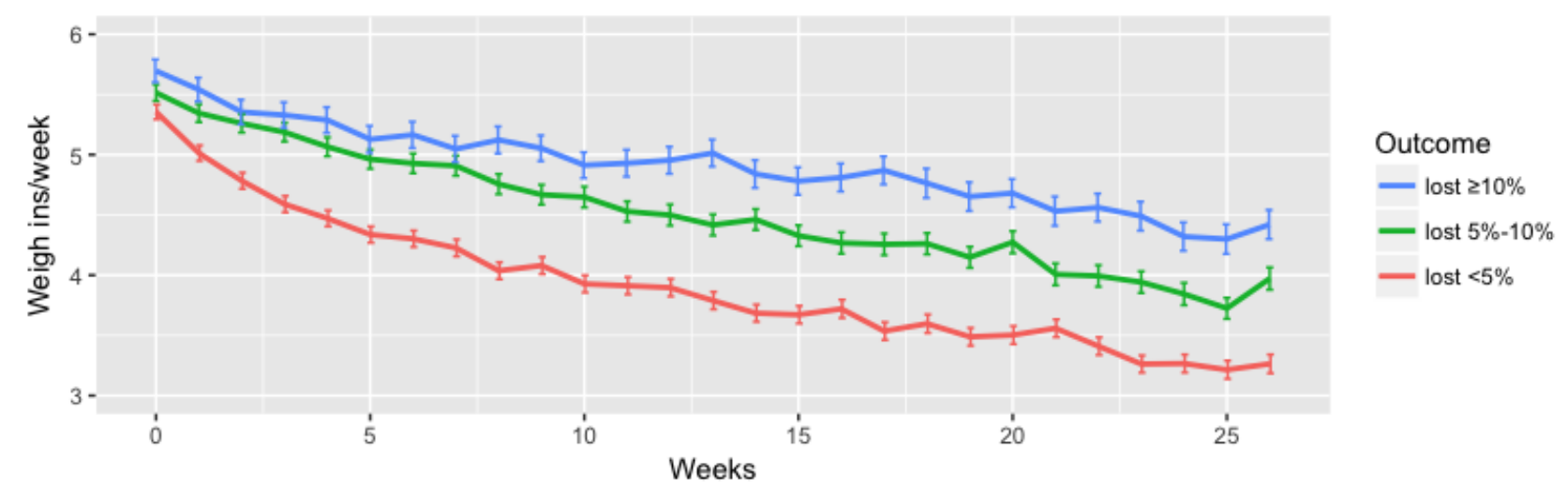

\section{Daily Steps}

Based on the steps data of participants between 0 and 6 months, a higher level of daily steps was significantly associated with a higher level of weight loss. Table 4 presents the results of the weight-loss analysis performed by dividing the participants to different levels of daily step counts. Daily steps of 5000 to 7499 or more were associated with clinically significant weight loss at 6 months. One-way ANOVA showed a significant difference in mean weight loss between different daily step levels $(P<.001)$. A subsequent Tukey test confirmed significant mean differences between all levels of daily steps $(P<.001)$. Similar ANOVA 
tests performed on male and female participants separately showed a significant difference in mean weight loss between the different daily step levels (male: $P<.001$; female: $P<.001$; see Multimedia Appendix 4, Table S4).

The analysis of daily steps of participants with different levels of weight loss showed that a higher daily step count was significantly associated with groups with higher levels of weight loss. Figure 3 presents the weekly mean steps per day among participants of three outcome levels. The lost $\geq 10 \%$ group consistently maintained significantly higher daily steps throughout the 6-month program. The mean daily steps over 6 months were mean 8077.79 (SE 171.52), mean 6657.09 (SE 117.13), and mean 5276.91 (SE 95.08) steps per day for the lost $\geq 10 \%$, lost $5 \%-10 \%$, and lost $<5 \%$ groups, respectively $(P<.001)$. Male and female participants separately showed a similar significant difference in mean daily steps between the different outcome levels (male: $P<.001$; female: $P<.001$; see Multimedia Appendix 4, Table S5).

\section{Highly Active Minutes}

Higher levels of highly active minutes were significantly associated with higher levels of weight loss. Percentage of weight loss was calculated by dividing the participants into different levels of highly active minutes per week (Table 4). Higher-intensity activity for 60 minutes or more per week was associated with clinically significant weight loss. There was a significant difference in mean weight loss between different weekly active minutes levels $(P<.001)$. A subsequent Tukey test showed significant differences between the " $\geq 180$ " active minutes level and the remaining three levels $(P<.001$ for all $)$ and between "120-179" active minutes level and " $<60$ " ( $P<.001)$ and between "60-119" active minutes level and " $<60$ " $(P<.001)$. Similar ANOVA tests performed on male and female participants separately showed a similar significant difference in mean weight loss between different daily highly active minutes levels (male: $P<.001$; female: $P<.001$, see Multimedia Appendix 4, Table S6).

The analysis of highly active minutes of the participants with different levels of weight loss showed that higher amounts of highly active minutes were significantly associated with groups with higher levels of weight loss. Figure 4 shows the weekly mean highly active minutes among participants in three outcome levels. Similar to daily steps, the lost $\geq 10 \%$ group consistently had a significantly higher level of high-intensity activity throughout the 6-month program. The mean weekly highly active minutes over 6 months were mean 154.33 (SE 6.47), mean 115.63 (SE 3.91), and mean 79.03 (SE 2.53) minutes per week for the lost $\geq 10 \%$, lost $5 \%-10 \%$, and lost $<5 \%$ groups, respectively $(P<.001)$. Male and female participants separately showed a similar significant difference in mean highly active minutes between different outcome levels (male: $P<.001$; female: $P<.001$; see Multimedia Appendix 4, Table S7).

Figure 3. Weekly mean steps per day of participants between 0 and 6 months. Error bars indicate the standard error of the mean.

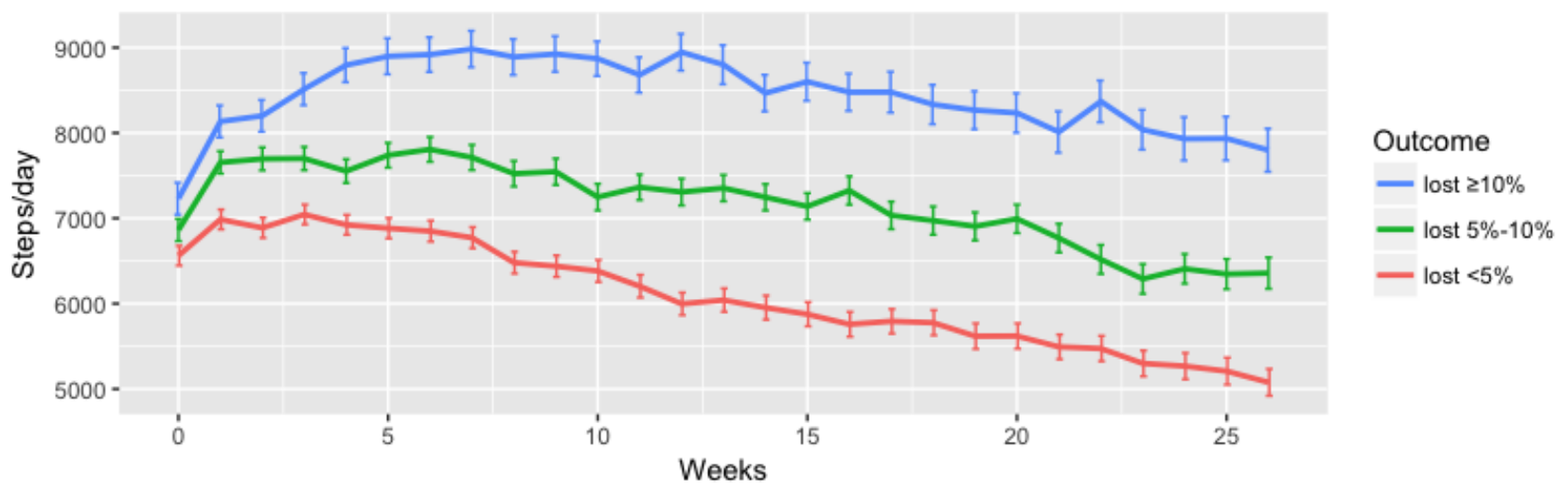

Figure 4. Weekly mean highly active minutes of participants between 0 and 6 months. Error bars indicate the standard error of the mean.

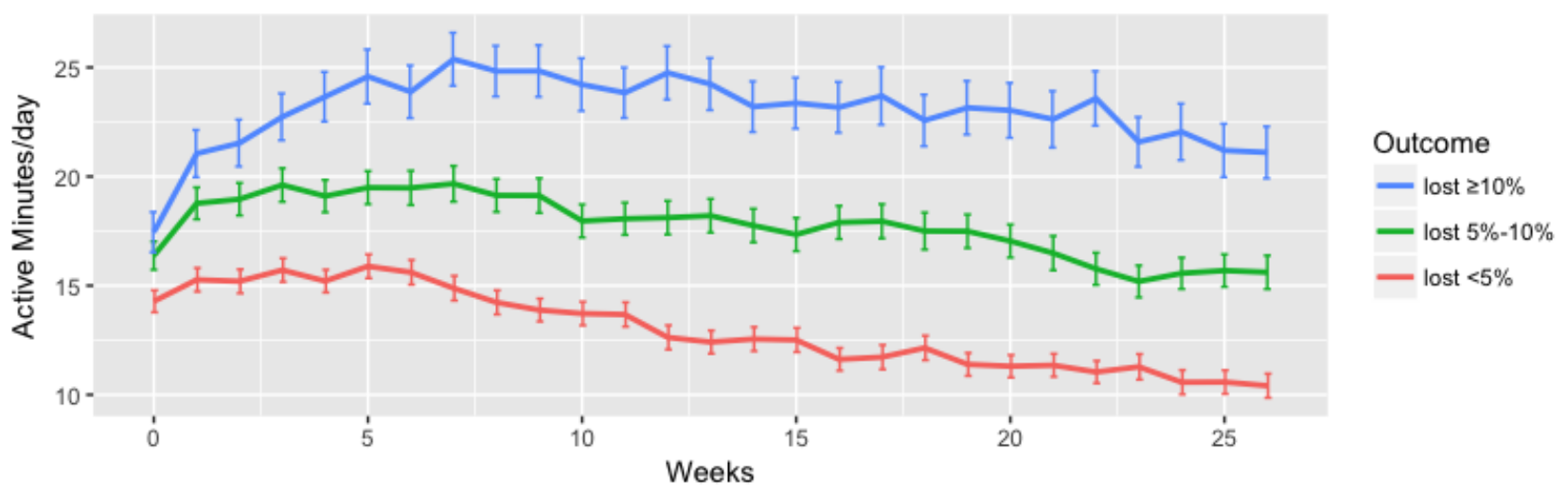




\section{Food Log Days}

Analysis of participants' food log data over 0 to 6 months showed that a higher number of food log days per week was significantly associated with a higher level of weight loss. Table 4 presents the weight-loss percentages of the groups of participants at different levels of food log days per week. Clinically significant weight loss was associated with at least three or more days of food logging per week. There was a significant difference in weight loss between different levels of weekly food $\log$ days $(P<.001)$. A subsequent Tukey test found significant differences between " $\geq 5$ " food log days and the remaining three levels ( $P<.001$ for all) and between " $3-4$ " and "1-2" food log days $(P=.03)$ and between " $3-4$ " and " $<1$ " food $\log$ days $(P<.001)$. Similar ANOVA tests performed on male and female participants separately showed a similar significant difference in mean weight loss between different numbers of food $\log$ days (male: $P<.001$; female: $P<.001$; see Multimedia Appendix 4, Table S8).

The analysis of food log days of the participants with different levels of weight loss showed that a higher number of food log days per week was significantly associated with groups with higher levels of weight loss. Figure 5 shows the weekly mean food log days among the participants in the three outcome levels. Participants in the higher outcome levels logged their food a significantly higher number of days throughout the 6-month program than the lowest outcome group. The mean weekly food log days over 6 months were mean 4.44 (SE 0.11), mean 3.92 (SE 0.08), and mean 2.90 (SE 0.60) days per week for the lost $\geq 10 \%$, lost $5 \%-10 \%$, and lost $<5 \%$ groups, respectively $(P<.001)$. Male and female participants separately showed a similar significant difference in mean food log days between different outcome levels (male: $P<.001$; female: $P<.001$; see Multimedia Appendix 4, Table S9).

\section{Percentage of Weeks With Five or More Food Logs}

Additional analysis of food logs showed that participants with a higher level of weight loss were significantly associated with a higher percentage of weeks with five or more food logs. There was a significant difference in percentage of weeks with five or more food logs between different weight loss outcome levels (lost $\geq 10 \%$ : mean 69.40\%, SE 1.72; lost 5\%-10\%: mean 63.61\%, SE 1.20 ; lost <5\%: mean $49.14 \%$, SE $0.97 ; P<.001)$. A subsequent Tukey test was performed, which found significant mean differences between all outcome levels (lost $\geq 10 \%$ and lost $<5 \%$ : $P<.001$; lost $\geq 10 \%$ and lost 5\%-10\%: $P=.01$; lost $5 \%-10 \%$ and lost $<5 \%$ : $P<.001)$. Additional ANOVA tests performed on male and female participants separately showed a similar significant difference in percentage of weeks with five or more food logs between the different outcome levels (male: $P<.001$; female: $P<.001$; see Multimedia Appendix 4, Table $\mathrm{S} 10)$.

Based on the analysis presented in previous sections, food logging is very critical for weight loss during the 6-month intervention. Hence, additional analysis is presented in Table 4 that shows the percentage weight loss for participants in different food log groups per week. A higher number of food logs per week was significantly associated with a higher level of weight loss $(P<.001)$. Further analysis to understand differences in weight-loss outcomes for male and female participants between different food log groups showed a similar difference (male: $P<.001$; female: $P<.001$; see Multimedia Appendix 4, Table S11).

\section{Discussion}

\section{Principal Findings}

The results provide strong support for the use of self-monitoring in weight-management programs. Participants who complied more with body weight, physical activity, and food intake self-monitoring lost more weight than those who complied less. In a multiple regression equation, each category of self-monitoring contributed significantly to the prediction of weight loss. Furthermore, the independent analysis showed a significant association between each self-monitoring behavior and weight loss. Overall, the use of self-monitoring was found to have a high impact on weight management.

Advances in technology, such as wireless scales and physical activity trackers, make it easier to self-monitor weight and physical activity, and are recommended in weight-management programs. Food logging still requires that a participant take time to record food intake, but technology has made it a faster and simpler process. However, there is a great need for developing new technology to reduce the time, effort, and accuracy in self-monitoring food intake.

Figure 5. Weekly mean food log days of participants between 0 and 6 months. Error bars indicate the standard error of the mean.

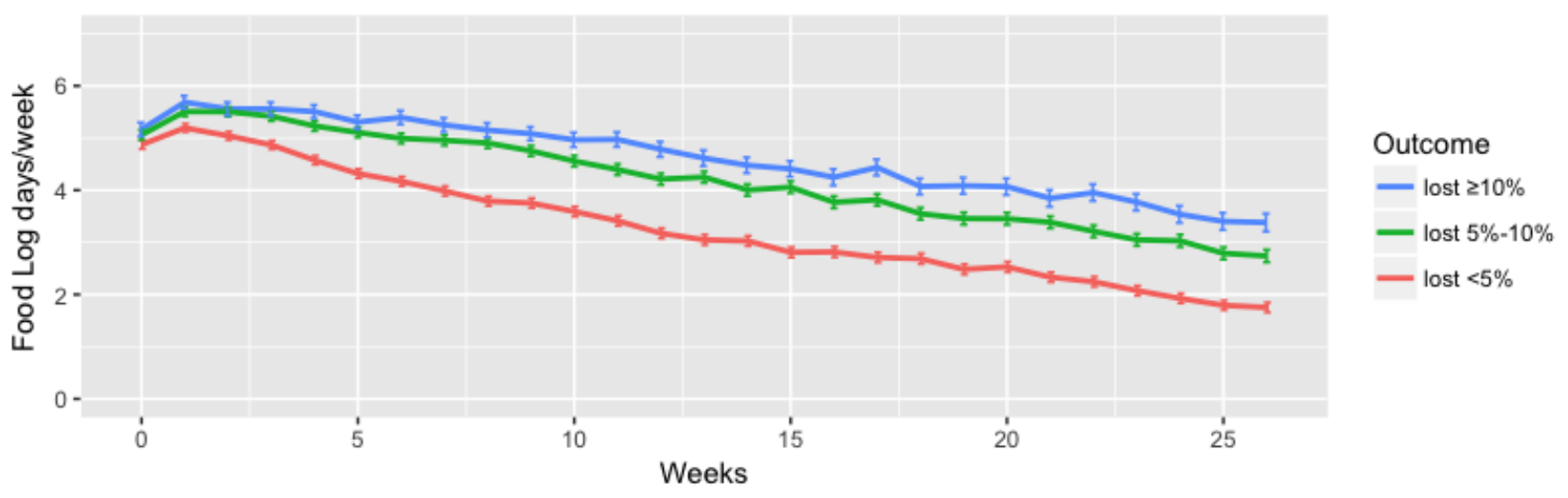


Some report that self-monitoring of single behaviors, such as body weight and physical activity $[2,27,40]$, may not be associated with greater weight loss. Our results found benefits of self-monitoring in each behavior category: weight, physical activity, and food intake. We found that self-monitoring all these behaviors together had the greatest predictive value for weight loss. Based on these results, it may be important to promote these self-monitoring behaviors together in an intervention or weight-loss program.

\section{Significant Predictors of Weight Loss}

\section{Self-Weigh-In}

The number of self-weigh-ins per week was identified as a significant predictor of weight loss $(P<.001)$. Self-weighing at least three times per week is associated with higher weight loss. An even higher level of weight loss is associated when weighing more than five times per week. Evidence has shown that instructing participants to weigh in at least three times per week does increase weight loss during an active weight-loss period, and a higher frequency of weighing in is associated with greater weight-loss success [15-18]. Additionally, females tend to weigh in more frequently than males, which is a unique finding due to an historically small percentage of male participants in weight-management studies and a lack of evidence around gender comparison [15-18,20,25,40-48].

\section{Daily Steps}

The number of steps per week $(P=.02)$ is a significant predictor of weight change. Higher step counts are associated with greater levels of weight loss, which has been shown in previous literature $[27,30,39]$. Also, our results confirm that men tend to have a higher daily step count than women, similar to that seen in the literature [26].

\section{Highly Active Minutes}

A minimum of 60 highly active minutes per week is significantly associated with higher levels of weight loss. Greater levels of highly active minutes are also significantly associated with higher weight loss outcomes. Males overall have a significantly higher level of active minutes than females at all weight-loss outcome levels $(P<.001)$. Currently, there is a lack of evidence around measuring active minutes with activity trackers associated with weight-loss outcomes. However, there is some evidence that men log more exercise than females and have a greater exercise dependence $[33,43,49]$.

\section{Food Log Days}

A higher number of food log days per week increases adherence to the self-monitoring behavior of food logging, which supports behavioral change as explained through self-regulation theory [31]. Food logging at least three days per week was significantly associated with higher levels of weight loss. Other studies have found that greater weight loss is achieved with a higher frequency of food logs, specifically three or more days per week [31-33,36,43].

\section{Percentage of Weeks With Five or More Food Logs}

A higher percentage of weeks with five or more food logs is significantly associated with higher levels of weight loss
$(P<.001)$. Additionally, the more times a participant logs their food per week increases their likelihood of successful weight loss [31-33]. Women tend to log their food more frequently than men do. However, this is a unique finding due to a historically small percentage of male participants in weight-management studies and a lack of evidence around gender comparison [31-35].

\section{Strengths and Limitations}

This study has several strengths, including the reporting of real-world weight-loss outcomes and providing a more focused analysis into weight-management behaviors to determine what behaviors are more significant in a behavioral weight-loss program. Participants were clients of Retrofit and not recruited or provided with incentives to participate in the study. All clients who met the starting BMI, age, and weight inclusion criteria and logged a weight at 6 months were included as participants and not removed from the population due to lack of success on the program, which is an uncommon research practice [44]. We conclude that this study adds value and brings a novel approach to the best practices around behaviors in weight management. Additionally, gender comparisons were able to be reported due to the unusually high population of males enrolled as participants, which is also a significant strength to understand which behaviors are more valuable to men and women in the weight-loss process.

The study also has some limitations, including the retrospective analysis study design, which does not allow any causal inferences based on the critical observations. Moreover, the adherence to different behaviors were evaluated using data from program completers, which limits the ability to generalize impact of the behavior on all participants. However, to determine effective levels of self-monitoring that can guarantee clinically significant weight loss, it is critical to study participants with known end weights. Lastly, due to use of the real-world population in this study, it is unknown if participants were integrating any other self-monitoring devices or practices outside of the Retrofit Program components.

\section{Future Research}

With a lack of real-world research in the commercial weight-loss industry, Retrofit encourages all commercial weight-loss programs to publish similar data to enhance understanding of which self-monitoring behaviors matter most in a weight-loss program. Reporting real-world data in relation to targeted behaviors allows commercial weight-loss programs to not only structure protocols and client strategies to increase weight-loss success, but also improve a participant's weight maintenance success. By narrowing in on the specific behaviors to build as life-long habits, commercial weight-loss programs will increase efficacy and establish our ability as an industry to overcome the obesity crisis.

Recommended future research includes studying self-monitoring behaviors beyond 6 months and each behavior's impact on weight maintenance. Also, further analysis around gender differences and self-monitoring behaviors is of interest to determine if specific behaviors should be encouraged more 
frequently among female versus male participants, specifically around food logging and activity levels.

\section{Conclusions}

In conclusion, participants on the Retrofit Program lost a mean $-5.58 \%$ (SE 0.12) and had a BMI change of mean -1.91 (SE $0.04)$ in 6 months with nearly $51.87 \%$ (1096/2113) of participants losing $5 \%$ or more of their baseline weight.
Self-monitoring behaviors, such as self-weigh-in, daily step counts, high-intensity activity, and persistent food logging were shown to be significant predictors of weight change at 6 months. Specifically, weighing in three times or more per week, having a minimum of 60 highly active minutes per week, food logging for three days or more per week, and having a higher percentage of weeks with five or more food logs increased participant's weight-loss success.

\section{Acknowledgments}

Members of the Retrofit Advisory Board provided comments and professional insight around the data and results.

\section{Conflicts of Interest}

SP, RA, SB, and AM are employees of Retrofit, Inc, with equity in the company. JH, RK, and RL are active members of the Retrofit, Inc Advisory Board, with equity in the company.

\section{Multimedia Appendix 1}

Retrofit logo.

\section{[JPG File, 64KB-Multimedia Appendix 1]}

\section{Multimedia Appendix 2}

The technology provided included a Wi-Fi-enabled scale, activity tracker, and access to a private dashboard. The dashboard was accessible via Web and mobile apps.

[PNG File, 135KB-Multimedia Appendix 2]

\section{Multimedia Appendix 3}

Retrofit client dashboard for logging food and exercise accessible via Web and mobile apps.

[PNG File, 167KB-Multimedia Appendix 3]

\section{Multimedia Appendix 4}

Supplementary Tables.

[PDF File (Adobe PDF File), 129KB-Multimedia Appendix 4]

\section{References}

1. Finkelstein EA, Haaland BA, Bilger M, Sahasranaman A, Sloan RA, Nang EE, et al. Effectiveness of activity trackers with and without incentives to increase physical activity (TRIPPA): a randomised controlled trial. Lancet Diabetes Endocrinol 2016 Dec;4(12):983-995. [doi: 10.1016/S2213-8587(16)30284-4] [Medline: 27717766]

2. Jakicic JM, Davis KK, Rogers RJ, King WC, Marcus MD, Helsel D, et al. Effect of wearable technology combined with a lifestyle intervention on long-term weight loss: the IDEA randomized clinical trial. JAMA 2016 Sep 20;316(11):1161-1171. [doi: 10.1001/jama.2016.12858] [Medline: 27654602]

3. Centers for Disease Control and Prevention. Adult obesity facts URL: https://www.cdc.gov/obesity/data/adult.html [accessed 2017-01-26] [WebCite Cache ID 6noA6pOKK]

4. Bray G, Bouchard C, James W, Wing R. Behavioral approaches to the treatment of obesity. In: Handbook of Obesity: Clinical Applications. New York: Marcel Dekker; 2004:147-167.

5. van der Mark M, Jonasson J, Svensson M, Linné Y, Rossner S, Lagerros YT. Older members perform better in an internet-based behavioral weight loss program compared to younger members. Obes Facts 2009;2(2):74-79. [doi: 10.1159/000209383] [Medline: 20054209]

6. Neve M, Morgan PJ, Jones PR, Collins CE. Effectiveness of web-based interventions in achieving weight loss and weight loss maintenance in overweight and obese adults: a systematic review with meta-analysis. Obes Rev 2010 Apr;11(4):306-321. [doi: 10.1111/j.1467-789X.2009.00646.x] [Medline: 19754633]

7. Tate DF, Wing RR, Winett RA. Using Internet technology to deliver a behavioral weight loss program. JAMA 2001 Mar 7;285(9):1172-1177. [Medline: 11231746] 
8. Gold BC, Burke S, Pintauro S, Buzzell P, Harvey-Berino J. Weight loss on the web: a pilot study comparing a structured behavioral intervention to a commercial program. Obesity (Silver Spring) 2007 Jan;15(1):155-164. [doi: 10.1038/oby.2007.520] [Medline: 17228043 ]

9. Harvey-Berino J, Pintauro S, Buzzell P, Gold EC. Effect of internet support on the long-term maintenance of weight loss. Obes Res 2004 Feb;12(2):320-329. [doi: 10.1038/oby.2004.40] [Medline: 14981225]

10. Polzien KM, Jakicic JM, Tate DF, Otto AD. The efficacy of a technology-based system in a short-term behavioral weight loss intervention. Obesity (Silver Spring) 2007 Apr;15(4):825-830. [doi: 10.1038/oby.2007.584] [Medline: 17426316]

11. Tate DF, Jackvony EH, Wing RR. A randomized trial comparing human e-mail counseling, computer-automated tailored counseling, and no counseling in an Internet weight loss program. Arch Intern Med 2006;166(15):1620-1625. [doi: 10.1001/archinte.166.15.1620] [Medline: 16908795]

12. Rothert K, Strecher VJ, Doyle LA, Caplan WM, Joyce JS, Jimison HB, et al. Web-based weight management programs in an integrated health care setting: a randomized, controlled trial. Obesity (Silver Spring) 2006 Feb;14(2):266-272 [FREE Full text] [doi: 10.1038/oby.2006.34] [Medline: 16571852]

13. Tate DF, Jackvony EH, Wing RR. Effects of Internet behavioral counseling on weight loss in adults at risk for type 2 diabetes: a randomized trial. JAMA 2003 Apr 9;289(14):1833-1836. [doi: 10.1001/jama.289.14.1833] [Medline: 12684363]

14. Womble LG, Wadden TA, McGuckin BG, Sargent SL, Rothman RA, Krauthamer-Ewing ES. A randomized controlled trial of a commercial internet weight loss program. Obes Res 2004 Jun;12(6):1011-1018. [doi: 10.1038/oby.2004.124] [Medline: 15229342]

15. Helander EE, Vuorinen A, Wansink B, Korhonen IK. Are breaks in daily self-weighing associated with weight gain? PLoS One 2014 Nov;9(11):e113164 [FREE Full text] [doi: 10.1371/journal.pone.0113164] [Medline: 25397613]

16. Pacanowski CR, Bertz FC, Levitsky DA. Daily self-weighing to control body weight in adults: a critical review of the literature. Sage Open 2014;4(4):1-16 [FREE Full text] [doi: 10.1177/2158244014556992] [Medline: 27127719]

17. Steinberg DM, Tate DF, Bennett GG, Ennett S, Samuel-Hodge C, Ward DS. Daily self-weighing and adverse psychological outcomes: a randomized controlled trial. Am J Prev Med 2014 Jan;46(1):24-29. [doi: 10.1016/j.amepre.2013.08.006] [Medline: 24355668]

18. Zheng Y, Klem ML, Sereika SM, Danford CA, Ewing LJ, Burke LE. Self-weighing in weight management: a systematic literature review. Obesity (Silver Spring) 2015 Feb;23(2):256-265. [doi: 10.1002/oby.20946] [Medline: 25521523]

19. Butryn ML, Webb V, Wadden TA. Behavioral treatment of obesity. Psychiatr Clin North Am 2011 Dec;34(4):841-859 [FREE Full text] [doi: 10.1016/j.psc.2011.08.006] [Medline: 22098808]

20. Steinberg DM, Tate DF, Bennett GG, Ennett S, Samuel-Hodge C, Ward DS. The efficacy of a daily self-weighing weight loss intervention using smart scales and e-mail. Obesity (Silver Spring) 2013 Sep;21(9):1789-1797 [FREE Full text] [doi: 10.1002/oby.20396] [Medline: 23512320]

21. Vanwormer JJ, Martinez AM, Martinson BC. Self-weighing promotes weight loss for obese adults. Am J Prev Med 2009;36(1):70-73. [Medline: 20151204]

22. Akers JD, Cornett RA, Savla JS, Davy KP, Davy BM. Daily self-monitoring of body weight, step count, fruit/vegetable intake, and water consumption: a feasible and effective long-term weight loss maintenance approach. J Acad Nutr Diet 2012 May;112(5):685-692 [FREE Full text] [doi: 10.1016/j.jand.2012.01.022] [Medline: 22709772]

23. Linde JA, Jeffery RW, French SA, Pronk NP, Boyle RG. Self-weighing in weight gain prevention and weight loss trials. Ann Behav Med 2005 Dec;30(3):210-216. [doi: 10.1207/s15324796abm3003 5] [Medline: 16336072]

24. Butryn ML, Phelan S, Hill JO, Wing RR. Consistent self-monitoring of weight: a key component of successful weight loss maintenance. Obesity (Silver Spring) 2007 Dec;15(12):3091-3096. [doi: 10.1038/oby.2007.368] [Medline: 18198319]

25. Bravata DM, Smith-Spangler C, Sundaram V, Gienger AL, Lin N, Lewis R, et al. Using pedometers to increase physical activity and improve health: a systematic review. JAMA 2007 Nov 21;298(19):2296-2304. [doi: 10.1001/jama.298.19.2296] [Medline: 18029834$]$

26. Bassett DR, Wyatt HR, Thompson H, Peters JC, Hill JO. Pedometer-measured physical activity and health behaviors in US adults. Med Sci Sports Exerc 2010 Oct;42(10):1819-1825 [FREE Full text] [doi: 10.1249/MSS.0b013e3181dc2e54] [Medline: 20305579]

27. Cai X, Qiu SH, Yin H, Sun ZL, Ju CP, Zügel M, et al. Pedometer intervention and weight loss in overweight and obese adults with Type 2 diabetes: a meta-analysis. Diabet Med 2016 Aug;33(8):1035-1044 [FREE Full text] [doi: 10.1111/dme.13104] [Medline: 26926674]

28. Musto A, Jacobs K, Nash M, DelRossi G, Perry A. The effects of an incremental approach to 10,000 steps/day on metabolic syndrome components in sedentary overweight women. J Phys Act Health 2010 Nov;7(6):737-745. [Medline: 21088304]

29. Cadmus-Bertram L, Marcus BH, Patterson RE, Parker BA, Morey BL. Use of the Fitbit to measure adherence to a physical activity intervention among overweight or obese, postmenopausal women: self-monitoring trajectory during 16 weeks. JMIR Mhealth Uhealth 2015;3(4):e96 [FREE Full text] [doi: 10.2196/mhealth.4229] [Medline: 26586418]

30. Conroy MB, Yang K, Elci OU, Gabriel KP, Styn MA, Wang J, et al. Physical activity self-monitoring and weight loss: 6-month results of the SMART trial. Med Sci Sports Exerc 2011 Aug;43(8):1568-1574 [FREE Full text] [doi: 10.1249/MSS.0b013e31820b9395] [Medline: 21200337] 
31. Burke LE, Wang J, Sevick MA. Self-monitoring in weight loss: a systematic review of the literature. J Am Diet Assoc 2011 Jan;111(1):92-102 [FREE Full text] [doi: 10.1016/j.jada.2010.10.008] [Medline: 21185970]

32. Krukowski RA, Harvey-Berino J, Bursac Z, Ashikaga T, West DS. Patterns of success: online self-monitoring in a web-based behavioral weight control program. Health Psychol 2013 Feb;32(2):164-170. [doi: 10.1037/a0028135] [Medline: 22545978]

33. Johnson F, Wardle J. The association between weight loss and engagement with a web-based food and exercise diary in a commercial weight loss programme: a retrospective analysis. Int J Behav Nutr Phys Act 2011 Aug 02;8(1):83 [FREE Full text] [doi: 10.1186/1479-5868-8-83] [Medline: 21810222]

34. Turk MW, Elci OU, Wang J, Sereika SM, Ewing LJ, Acharya SD, et al. Self-monitoring as a mediator of weight loss in the SMART randomized clinical trial. Int J Behav Med 2013 Dec;20(4):556-561 [FREE Full text] [doi: 10.1007/s12529-012-9259-9] [Medline: 22936524]

35. Hutchesson MJ, Tan CY, Morgan P, Callister R, Collins C. Enhancement of self-monitoring in a web-based weight loss program by extra individualized feedback and reminders: randomized trial. J Med Internet Res 2016 Apr 12;18(4):e82 [FREE Full text] [doi: 10.2196/jmir.4100] [Medline: 27072817]

36. Carter MC, Burley VJ, Nykjaer C, Cade JE. Adherence to a smartphone application for weight loss compared to website and paper diary: pilot randomized controlled trial. J Med Internet Res 2013;15(4):e32 [FREE Full text] [doi: 10.2196/jmir.2283] [Medline: 23587561]

37. Retrofit. URL: https://www.retrofitme.com/ [accessed 2017-05-06] [WebCite Cache ID 6qG26LCBV]

38. Painter S, Ditsch G, Ahmed R, Hanson NB, Kachin K, Berger J. Retrofit weight-loss outcomes at 6, 12, and 24 months and characteristics of 12-month high performers: a retrospective analysis. JMIR Mhealth Uhealth 2016 Aug 22;4(3):e101 [FREE Full text] [doi: 10.2196/mhealth.5873] [Medline: 27549134]

39. Dwyer T, Hosmer D, Hosmer T, Venn AJ, Blizzard CL, Granger RH, et al. The inverse relationship between number of steps per day and obesity in a population-based sample: the AusDiab study. Int J Obes (Lond) 2007 May;31(5):797-804. [doi: 10.1038/sj.ijo.0803472] [Medline: 17047641$]$

40. Madigan CD, Daley AJ, Lewis AL, Aveyard P, Jolly K. Is self-weighing an effective tool for weight loss: a systematic literature review and meta-analysis. Int J Behav Nutr Phys Act 2015 Aug 21;12:104 [FREE Full text] [doi: 10.1186/s12966-015-0267-4] [Medline: 26293454]

41. Saad L. Gallup. 2011. To lose weight, Americans rely more on dieting than exercise URL: http://www.webcitation.org/ 6qD3hIfW7 [accessed 2017-05-04] [WebCite Cache ID 6qD3hIfW7]

42. Wadden TA, Webb VL, Moran CH, Bailer BA. Lifestyle modification for obesity: new developments in diet, physical activity, and behavior therapy. Circulation 2012 Mar 6;125(9):1157-1170 [FREE Full text] [doi: 10.1161/CIRCULATIONAHA.111.039453] [Medline: 22392863]

43. Serrano KJ, Yu M, Coa KI, Collins LM, Atienza AA. Mining health app data to find more and less successful weight loss subgroups. J Med Internet Res 2016 Jun 14;18(6):e154 [FREE Full text] [doi: 10.2196/jmir.5473] [Medline: 27301853]

44. Gudzune KA, Bleich SN, Clark JM. Efficacy of commercial weight-loss programs. Ann Intern Med 2015 Sep 1;163(5):399. [doi: 10.7326/L15-5130-3] [Medline: 26322706]

45. Wing RR, Lang W, Wadden TA, Safford M, Knowler WC, Bertoni AG, Look AHEAD Research Group. Benefits of modest weight loss in improving cardiovascular risk factors in overweight and obese individuals with type 2 diabetes. Diabetes Care 2011 Jul;34(7):1481-1486 [FREE Full text] [doi: 10.2337/dc10-2415] [Medline: 21593294]

46. Appel LJ, Clark JM, Yeh H, Wang N, Coughlin JW, Daumit G, et al. Comparative effectiveness of weight-loss interventions in clinical practice. N Engl J Med 2011 Nov 24;365(21):1959-1968 [FREE Full text] [doi: 10.1056/NEJMoa1108660] [Medline: 22085317]

47. Almeida FA, You W, Harden SM, Blackman KC, Davy BM, Glasgow RE, et al. Effectiveness of a worksite-based weight loss randomized controlled trial: the worksite study. Obesity (Silver Spring) 2015 Apr;23(4):737-745 [FREE Full text] [doi: 10.1002/oby.20899] [Medline: 25678325]

48. Arem H, Irwin M. A review of web-based weight loss interventions in adults. Obes Rev 2011 May;12(5):e236-e243 [FREE Full text] [doi: 10.1111/j.1467-789X.2010.00787.x] [Medline: 20804523]

49. Weik M, Hale BD. Contrasting gender differences on two measures of exercise dependence. Br J Sports Med 2009 Mar;43(3):204-207. [doi: 10.1136/bjsm.2007.045138] [Medline: 18308882]

\section{Abbreviations}

BMI: body mass index 
Edited by $G$ Eysenbach; submitted 09.02.17; peer-reviewed by L Chai, J Chaplin; comments to author 24.02.17; revised version received 27.03.17; accepted 14.04.17; published 12.05.17

Please cite as:

Painter SL, Ahmed R, Hill JO, Kushner RF, Lindquist R, Brunning S, Margulies A

What Matters in Weight Loss? An In-Depth Analysis of Self-Monitoring

J Med Internet Res 2017;19(5):e160

URL: http://www.jmir.org/2017/5/e160/

doi: 10.2196/jmir.7457

PMID: 28500022

(CStefanie Lynn Painter, Rezwan Ahmed, James O Hill, Robert F Kushner, Richard Lindquist, Scott Brunning, Amy Margulies. Originally published in the Journal of Medical Internet Research (http://www.jmir.org), 12.05.2017. This is an open-access article distributed under the terms of the Creative Commons Attribution License (http://creativecommons.org/licenses/by/2.0/), which permits unrestricted use, distribution, and reproduction in any medium, provided the original work, first published in the Journal of Medical Internet Research, is properly cited. The complete bibliographic information, a link to the original publication on http://www.jmir.org/, as well as this copyright and license information must be included. 